Appleyard, R. K. (1956). J. gen. Microbiol. 14, 573-582

\title{
The Transfer of Defective Lambda Lysogeny between Strains of Escherichia coli
}

\author{
BY R. K. APPLEYARD \\ Biology Division, Alomic Energy of Canada, Ltd., Chalk River, Ontario, Canada
}

SUMMARY: The infective transfer of defective lambda lysogeny from a defective prophage to sensitive Escherichia coli has been observed. The agent of transfer appears to be lambda phage in which has been incorporated the hereditary defective element. It is concluded that the existence of the phage genes responsible for defective lysogeny is not limited to the prophage condition.

Those strains of Escherichia coli which are lysogenic for phage lambda may be induced to liberate phage by exposing the organisms to ultraviolet (u.v.) light: each induced organism subsequently liberates about 100 lambda phage particles (Weigle \& Delbrück, 1951). There exist, however, defective lambda lysogenic organisms in which the yield of phage particles averages less than $10^{-5} /$ induced bacterium. The cause of this defect appears to be a mutation of a prophage gene, for it recombines with other prophage markers during the bacterial growth of a doubly lysogenic strain (Appleyard, 1954b). Unlike all other prophage genes, the one responsible for defective lysogeny has been observed to affect only the number of mature phage particles liberated after induction of bacteria carrying the defective prophage; none of the phage liberated has yet been shown to transmit the defect. As long as this is true, the genetic status of the defect remains in doubt. The 'mutation' might, for example, be no more than a change in relationship between part of an unaltered prophage and the genetic apparatus of the bacterium. Such a relationship has meaning only in the lysogenic complex, so that any mutation of this kind would be inherently restricted to the prophage condition. I have therefore designed experiments to find out whether the mutation responsible for defective lysogeny can be transmitted by extracellular lambda phage.

\section{METHODS}

Bacteria and bacteriophages. Lambda phage and some of its mutants, together with sensitive and lysogenic strains of Escherichia coli, were described previously (see Appleyard, 1954a, $b$ ). In the present paper prophage defects of independent occurrence are denoted as $i_{1}, i_{2}, \ldots$, etc. Thus, of the strains previously described $\mathrm{C} 60$ becomes $\mathrm{C} 60\left(\lambda i_{1}\right)$, and the defective lysogenic strain derived from $E$. coli $\mathrm{K} 12$ by 2 min. u.v. irradiation becomes C $33\left(\lambda i_{2}\right)$.

Methods. The methods used were those previously described (Appleyard, $1954 a, b)$, with the additions and modifications noted below.

Magnesium and other supplements. Observations kindly communicated to me by A. D. Kaiser have led me to supplement all media, unless otherwise stated, 
with $0 \cdot 25 \%(\mathrm{w} / \mathrm{v}) \mathrm{MgSO}_{4} \cdot 7 \mathrm{H}_{2} \mathrm{O}$ in order to improve lambda absorption. Traces of $\mathrm{Ca}$ and $\mathrm{Fe}$ and $5 \mu \mathrm{g}$. thiamine hydrochloride/ml. were also added to all growth media.

Techniques involving weak virulent lambda-v 1. (1) Cross-streak test. The primary technical problem throughout was to detect and assay defective lysogenic organisms among the survivors of experimental lambda infections, which include both sensitive organisms and lambda-resistant mutants. In contrast to these, both defective and non-defective ('healthy') lysogens are immune to weak virulent lambda-v 1 but sensitive to strong virulent lambda-v2. In cross-streak tests all four types of organism may be identified as in Table 1. This cross-streak scheme was my basic method of identification of organisms carrying defective lambda prophage. Colonies which resist lambda phage because they do not adsorb it cannot be tested for lysogeny by cross-streaking against lambda-v 1 . These were never sufficiently numerous to cause any appreciable error in my experiments.

Table 1. Cross-streak method for the identification of defective lysogenic organisms

\begin{tabular}{|c|c|c|c|c|}
\hline Cross-streak against: & $\ldots$ & $\begin{array}{c}\operatorname{lambda}_{\mathrm{v} 1} \\
\quad\end{array}$ & $\begin{array}{c}\text { lambda- } \\
\quad \text { v } 2\end{array}$ & $\begin{array}{c}\text { Sensitive } \\
\text { organisms }\end{array}$ \\
\hline \multicolumn{5}{|l|}{ Type of colony } \\
\hline$L a m b d a$ resistant $\left(V_{\lambda}{ }^{r}\right)$ & & $\mathbf{R}$ & $\mathbf{R}$ & - \\
\hline Healthy lysogenic $\left(\boldsymbol{L} p^{+}\right)$ & & $\mathbf{R}$ & $\mathbf{S}$ & + \\
\hline Defective lysogenic $\left(L p^{i}\right)$ & & $\mathbf{R}$ & $\mathbf{S}$ & - \\
\hline Lambda sensitive $\left(L p^{s}\right)$ & & $\mathbf{S}$ & $\mathrm{s}$ & - \\
\hline
\end{tabular}

$\mathbf{R}=$ resistant: continuous streak; $\mathbf{S}=$ sensitive: broken streak. $+=$ lysogenic: clear area around streak; $-=$ non-lysogenic: no clear area around streak.

(2) Replica test. The cross-streak method becomes impractical when sufficient survivors of infection must be examined to obtain significant quantitative results. In some early experiments I partially overcame this difficulty by destroying most of the sensitive survivors with a great excess of lambda-v 1 . Later I devised the following lambda-v 1 replica test.

On a nutrient plate is poured a top layer consisting of $0.1 \mathrm{ml}$. of a lambda-v 1 suspension whose titre exceeds $2 \times 10^{11}$ plaque-forming particles $/ \mathrm{ml}$., well mixed with $3 \mathrm{ml} .1 .5 \%$ nutrient agar. The plate is stored at $4^{\circ}$. When it is desired to examine a plate on which colonies have grown from the organisms which survived an experimental lambda infection, test colonies are imprinted on the lambda-v1-seeded plate by the usual velveteen method (Lederberg \& Lederberg, 1952). The plates are incubated for 4-6 hr. at $37^{\circ}$ and examined. The replicas of sensitive colonies appear as very thin spotted growth, while those of the other three classes in Table 1 appear as normal thick growths. In this way lambda-sensitive organisms on the original plate are identified.

Double replica test. The method just described is generally used in conjunction with a second replication of the same original plate on to a plate seeded with sensitive bacteria; this second replica plate is then exposed before 
incubation to u.v. light for 15 sec. Organisms from a healthy lysogenic colony imprinted on the plate are thereby induced to liberate phage particles which form a clear area or halo round the replica colony : these halos therefore enable healthy lysogenic colonies on the original plate to be identified. Colonies which contain neither sensitive nor healthy lysogenic organisms are provisionally classed as consisting of defective lysogenic organisms and are picked, grown in nutrient broth and retested by the full cross-streak scheme of Table 1, which also serves to eliminate truly lambda-resistant organisms. I confirmed by picking and cross-streaking, that healthy lysogenic colonies could be reliably counted from the halos on the appropriate replica plates: thus only suspected defective lysogens needed to undergo the full cross-streak test. Sectored or mixed colonies were disregarded when counting either healthy or defective lysogens, since a much smaller sector could be recognized as healthy lysogenic than as defective lysogenic. The method was found to be quantitatively accurate in tests made on artificial mixtures of defective and healthy lysogenic with sensitive organisms.

Preparations of phage suspensions. To prepare phage suspensions from doubly lysogenic and other strains, I selected bacterial derivatives resistant to lambda $\left(V_{\lambda}^{r}\right)$ so as to prevent readsorption of phage and proceeded as follows.

A saturated (overnight) culture was diluted 1/2000 in fresh broth and grown with aeration at $37^{\circ}$ to a viable bacterial count of $3 \times 10^{8} / \mathrm{ml}$. (approx. $2 \frac{3}{4} \mathrm{hr}$.). The suspension was centrifuged at $2000 \mathrm{~g}$ for $10 \mathrm{~min}$., the supernatant fluid discarded and the pellet resuspended in buffer. The resuspended bacteria were exposed to u.v. for 15 sec. in a layer not more than $1 \mathrm{~mm}$. thick, while the vessel was gently swirled by hand. Larger volumes $(200 \mathrm{ml}$.) were occasionally irradiated in thicker layers with mechanical stirring, and a suitably adjusted dose of u.v. irradiation. To the suspension was added one-ninth its volume of a solution of $10 \%$ tryptone. The irradiated culture was then aerated at $37^{\circ}$. Precautions were taken to prevent photoreactivation for the first $30 \mathrm{~min}$. after induction; $120 \mathrm{~min}$. after the addition of tryptone, the suspension was assayed for phage, suitably sterilized and re-assayed. Sterilization was carried out either by filtration or by shaking with sufficient chloroform to saturate the aqueous phase. In the latter case the suspension can be stored over chloroform in the cold. In agreement with Markovitch (1954) I found a slight but uniform decrease in phage titre on shaking with commercial chloroform. Suspensions which were to be compared with cyanide-treated suspensions were dialysed immediately after chloroform treatment (see below).

Cyanide + chloroform dialysis technique. I occasionally found it desirable to control the burst size in different portions of the same u.v.-induced culture. In agreement with Weigle \& Delbrück (1951), I found the addition of cyanide to be satisfactory, provided that this was done not less than $50 \mathrm{~min}$. after induction. Phage liberation was complete about $20 \mathrm{~min}$. after the cyanide was added. I used the procedure described below.

A culture was grown and irradiated as described earlier; 45 min. later it was divided into suitable portions in separate bubbler tubes. At various times 
thereafter $(t)$, potassium cyanide was added to the individual tubes to a final concentration of $0.01 \mathrm{M}$. At time $t+30 \mathrm{~min}$. each tube was shaken with chloroform and at once pipetted into a sack formed of dialysis tubing previously sterilized by autoclaving. The neck of the sack was tied round a glass tube plugged with cotton-wool to permit sterile access. The sack was at once suspended in about $3 \mathrm{l}$. sterile ice-cold nutrient broth or buffer and allowed to dialyse for $\mathbf{2 4} \mathrm{hr}$. Dialysis was repeated against fresh liquid for a further $24 \mathrm{hr}$. and the phage stock withdrawn with a volumetric pipette. The last residue in the sack was generally discarded, as it was apt to contain precipitated material. I usually relied solely on convection and an occasional swirl by hand for the necessary stirring. No change of phage titre was observed during the dialysis procedure, nor untoward effects of cyanide or chloroform in working with suspensions prepared in this manner.

\section{RESULTS}

It is convenient to consider the transmission of defective lysogeny from one organism to another by extracellular phage in terms of three separate postulates:

(i) That sensitive bacteria can acquire defective lysogeny as a consequence of infection by a cell-free phage suspension which has been prepared through the u.v.-induction of suitable lysogenic organisms.

(ii) That only those suspensions which originate from bacteria containing a defective prophage can transmit defective lysogeny, under the conditions of (i).

(iii) That the infective agent responsible for the transfer of defective lysogeny is lambda phage.

The experimental evidence for each of these postulates will be described in turn.

The acquisition of defective lysogeny by sensitive bacteria

I reasoned that phage in which the genetic defect of the prophage had been incorporated was a priori most likely to be found in the phage suspensions prepared by u.v. induction of doubly lysogenic bacteria having one healthy and one defective prophage; such an arrangement ensures that the healthy prophage carries out all the activities related to the vegetative growth and maturation of lambda phage in the immediate presence of the genetic defect. In consequence, I worked extensively with cell-free phage suspensions of this kind. The results of a typical experimental infection of sensitive bacteria by such a suspension are shown in Table 2 . The defective lysogenic survivors of infection were counted by the double replica method confirmed by cross-streaking against both weakly virulent (v1) and strongly virulent (v2) lambda phage, and it was necessary to show that this cross-streak test reliably selected defective lysogenic colonies under the conditions of our experiment. That the characteristic resistance to lambda-v1, but not to $l a m b d a-\mathrm{v} 2$, is a hereditary property of the bacteria of such a colony, and not a temporary phenomenon due to a mixture of cell-types, was shown by 
respreading samples of 10 colonies and re-testing 10 subcolonies derived from each. All 100 subcolonies possessed the same characteristic resistance pattern as their parents. That the resistance pattern was a true indication of defective lysogeny was shown by examining a total of 46 such colonies drawn from several experiments (including second-generation colonies from the 10 just mentioned). From each, a broth culture was grown to the end of the logarithmic phase, induced by 15 sec. u.v. irradiation and the organisms resuspended

Table 2. Infective acquisition of defective lysogeny by sensitive organisms from a phage suspension prepared by $u . v$. induction of CR751 $\left(\lambda i_{1}, \lambda \mathrm{v} 1\right)$

\begin{tabular}{|c|c|c|}
\hline Infection tube & $\begin{array}{l}\text { Input of sensitive organisms } \\
\text { Input of lambda } \\
\text { Adsorbed lambda } \\
\text { Bacteria yielding phage } \\
\text { Bacteria surviving infection }\end{array}$ & $\begin{array}{l}2.8 \times 10^{8} / \mathrm{ml} \\
4 \cdot 2 \times 10^{8} / \mathrm{ml} \\
3 \cdot 7 \times 10^{8} / \mathrm{ml} \\
1 \cdot 3 \times 10^{8} / \mathrm{ml} \\
1 \cdot 2 \times 10^{8} / \mathrm{ml}\end{array}$ \\
\hline Bacterial survivors & $\begin{array}{l}\text { Defective lysogenic } \\
\text { Healthy lysogenic } \\
\text { Sensitive organisms } \\
\text { Genetically resistant organisms }\end{array}$ & $\begin{array}{l}6 \cdot 5 \pm 0 \cdot 7 \times 10^{6} / \mathrm{ml} \\
3 \cdot 2 \pm 0 \cdot 13 \times 10^{7} / \mathrm{ml} \\
7 \cdot 9 \pm 0 \cdot 5 \times 10^{7} / \mathrm{ml} \\
0\left(<5 \times 10^{4} / \mathrm{ml}\right)\end{array}$ \\
\hline Uninfected culture & $\begin{array}{l}\text { Sensitive organisms } \\
\text { Others ( } 2490 \text { colonies examined) }\end{array}$ & $\begin{array}{l}1 \cdot 3 \times 10^{9} / \mathrm{ml} . \\
0\left(<6 \times 10^{5} / \mathrm{ml} .\right)\end{array}$ \\
\hline
\end{tabular}

Sensitive organisms grown to a viable count of about $10^{\%} / \mathrm{ml}$. were mixed at $37^{\circ}$ with a phage suspension in nutrient broth. $15 \mathrm{~min}$. were allowed for adsorption. Bacterial survivors and organisms plated directly from the uninfected sensitive culture were classified by the double replica method confirmed by cross-streaking. \pm : standard deviation due to purely statistical errors. $0(<n)$ : one observed would have corresponded to $n$.

in broth. In every case the optical density of the culture fell precipitately 80-90 min. later, and after $120 \mathrm{~min}$. a yield of between $5 \times 10^{-8}$ and $5 \times 10^{-5}$ phage particles/bacterium exposed to u.v. was present in the suspension. These are the characteristic properties which define the defective lysogeny under investigation (Appleyard, 1954 $b$ ). Results similar to those of Table 2 were obtained by another method, in which those genetically sensitive bacteria which survived infection were destroyed through immediate exposure of all the survivors to a high multiplicity of weak virulent lambda.

In the course of 40-50 experiments, by both methods, in which infection of sensitive bacteria was followed by the recovery of defective lysogenic organisms, I did not observe even one defective lysogenic bacterium in the uninfected sensitive cultures. I conclude that sensitive bacteria can acquire defective lysogeny from certain phage suspensions.

\section{The transfer of defective lysogeny}

It remains possible that, in the experiments $I$ have described, defective lysogeny arose by some form of aberrant infection rather than by transfer. To eliminate this possibility, it was necessary to show that a phage suspension could only confer defective lysogeny upon sensitive cells if it originated from bacteria which carried a defective prophage. Each such suspension was therefore compared with an otherwise identical suspension prepared from organisms 
which contained only healthy prophage. I first superinfected two singly lysogenic strains of Escherichia coli, one carrying a defective, the other a healthy but otherwise identical prophage, with the same suspension of the phage mutant lambda-cl and so prepared a pair of doubly lysogenic bacterial strains identical in bacterial and phage genotype, except that one of them carried a defect in one prophage. Phage suspensions were made from both strains by u.v. induction and assayed for their ability to confer defective lysogeny. As the measure of this ability $I$ used the ratio of defective to healthy lysogenics $\left(L p^{i} / L p\right)$, which they formed upon infection of identical sensitive organisms.

The results of such an experiment are shown in Table 3, of which the last column shows that the ability to confer defective lysogeny was restricted to the phage suspensions prepared by $\mathrm{u} . \mathrm{v}$. induction of the strain $\mathrm{C} 112\left(\lambda i_{1}, \lambda c l\right)$ containing a defective prophage. In principle, such a restriction might appear to exist if, when a suspension of phage was prepared, its ability to confer defective lysogeny were very strongly correlated with the average yield of healthy phage particles per induced bacterium, that is, with the burst size. To eliminate this possibility three phage suspensions were made and compared (Table 3) the burst sizes being: (1) low (2.8); (2) high (29); (3) intermediate (15). The necessary low average yields were obtained by the cyanide procedure mentioned earlier.

Table 3. The ability of phage suspensions to confer defective lysogeny upon sensitive organisms, and its correlation with descent from a defective prophage

\begin{tabular}{|c|c|c|c|c|}
\hline Origin of phage suspension & $\begin{array}{l}\text { Bacterial } \\
\text { survivors of } \\
\text { test infection } \\
\text { examined }\end{array}$ & $\begin{array}{c}\text { Defective } \\
\text { lysogenics } \\
\left(L p^{i}\right)\end{array}$ & $\begin{array}{c}\text { Healthy } \\
\text { lysogenics } \\
\left(L p^{+}\right)\end{array}$ & $\begin{array}{c}L p^{i} / \\
L p^{+} \times 100\end{array}$ \\
\hline From defective prophage, by u.v. (1) & 2500 & 16 & 234 & $6 \cdot 8 \pm 1 \cdot 8$ \\
\hline induction of $\mathrm{C} 112\left(\lambda i_{1}, \lambda c \mathrm{l}\right)$ & 8000 & 18 & 181 & $9 \cdot 9 \pm 2 \cdot 4$ \\
\hline $\begin{array}{l}\text { From healthy prophage only, by } \\
\text { u.v. induction of C } 112 \\
(\lambda+, \lambda c l)\end{array}$ & 3200 & 0 & 248 & $0(<0 \cdot 4)$ \\
\hline
\end{tabular}

Each suspension infected part of the same culture of sensitive organisms (C600) and was assayed as in Table 2 . \pm : standard deviation due to purely statistical errors; $0(<n)$ : one observed would have corresponded to $n$.

Any comparison of the kind just described includes, as well as a doubly lysogenic strain with a defect in one of its prophages, a similar strain without the defect. I therefore wished in each case to demonstrate the presence or absence of the lysogenic defect by a method independent of the origin of the doubly lysogenic strain. To do this, I used the tendency previously reported (Appleyard, 1954b) for the prophage characters of doubly lysogenic strains to segregate during bacterial growth.

Portions of fully grown cultures were suitably diluted and spread upon nutrient plates. The colonies which grew up were tested for lysogeny by replica 
plating, the predominant type giving rise to mottled halos. Those colonies which arose from bacterial segregants that had lost one or more prophage characters were counted according to the following scheme:

(i) Clear halo $(c l)$ : colony has lost the prophage character for turbid plaque formation and retained only that for clear plaque formation.

(ii) Turbid halo $(t)$ : colony has lost the prophage character for clear plaque formation and retained only that for turbid plaque formation.

(iii) No halo $(i)$ : colony has lost all healthy and contains only defective prophages.

The ratio of the third class of segregants to the sum of the first two, $i /(t+c l)$, was considered to provide a quantitative test for the presence or absence of defective prophage, whatever the overall frequency of segregations. The application of the method to the bacterial strains mentioned in Table 3 is shown in Table 4.

Table 4. Segregation of defect in doubly lysogenic strains

\begin{tabular}{|c|c|c|c|}
\hline \multirow[b]{2}{*}{ Strain } & \multicolumn{3}{|c|}{ Segregants observed } \\
\hline & $\begin{array}{c}\text { Clear or } \\
\text { turbid halo } \\
\quad(t+c l)\end{array}$ & $\begin{array}{l}\text { No halo } \\
\text { (i) }\end{array}$ & $i /(t+c l)$ \\
\hline $\begin{array}{l}\mathrm{C} 112\left(\lambda i_{1}, \lambda c l\right) \\
\mathrm{C} 112(\lambda+, \lambda c l)\end{array}$ & $\begin{array}{r}35 \\
202\end{array}$ & $\begin{array}{r}51 \\
0\end{array}$ & $\begin{array}{c}1 \cdot 45 \\
0(<0.005)\end{array}$ \\
\hline
\end{tabular}

The halos were observed around replica colonies on plates seeded with sensitive bacteria. The plates were exposed to u.v. for $15 \mathrm{sec}$. after replication but before incubation. $0(<n)$ : one observed would have corresponded to $n$.

The restriction demonstrated in Tables 3 and 4 still holds when the lysogenic defect $i_{2}$ is employed instead of $i_{1}$. It is unaffected by the bacterial genotype of either the strains from which the phage suspensions are prepared or the sensitive bacteria upon which defective lysogeny is conferred: either culture can be $\mathbf{F}^{+}, \mathbf{F}^{-}$, prototrophic or multiply auxotrophic (leucine, threonine, thiamine dependent, or cystine, histidine dependent).

The fact that a phage suspension can confer defective lysogeny upon lambdasensitive bacteria when and only when it is descended from defective prophage implies that the defect in the newly formed lysogenic bacteria does not, under the conditions of my experiments, arise de novo at infection, but is in each case transferred from the original defective prophage by some agent in the phagecontaining suspension. The bacterial strain $\mathrm{C} 112\left(\lambda i_{1}, \lambda c l\right)$ of Table 3 originally obtained its defective prophage by infection. The experiment described in Table 3 is therefore an example of serial transfer of defective lysogeny.

\section{Identification of the agent of transfer with lambda phage}

I compared three properties of the carrier of the lysogenic defect in suspensions which contain it with those of the plaque-forming phage present in the same suspensions. In each case the suspension was partitioned or treated so as to modify grossly its content of lambda plaque-forming particles. 
The ratio of defective to healthy lysogenic organisms formed by the suspension among sensitive bacteria was measured before and after treatment. Tables 5-7 show that within the limits of experimental error the carrier of defective lysogeny had the same mass as lambda phage, the same rate of inactivation by specific anti-lambda serum, and the same rate of absorption by bacteria which absorbed lambda ( $\boldsymbol{V}_{\lambda}^{s}$ organisms). I regard these three properties as sufficient to identify the agent of transfer of defective lysogeny with lambda phage.

Table 5. Centrifugal test of identity of carrier of defective lambda lysogeny with lambda phage

Infecting phage

Original suspension (prepared from u.v. induced CR 751 $\left.\left(\lambda i_{1}, \lambda \mathrm{vl}\right)\right)$

Precipitate (c. $80 \%$ of phage)

Supernatant (c. $10 \%$ of phage)
Ratio of defective to healthy lysogenics formed in sensitive organisms : $\boldsymbol{L} p^{i} / \boldsymbol{L} p^{+} \times 100$ $13 \pm 3 \cdot 0$ $9 \cdot 4 \pm 2 \cdot 3$ $12 \pm 2 \cdot 7$

$10 \mathrm{ml}$. of the suspension were spun for $2 \mathrm{hr}$. in the cold at $25,000 \mathrm{~g}$ (sufficient to precipitate $80 \%$ of the phage). The top $8 \mathrm{ml}$. of supernatant were withdrawn and the pellet was resuspended in the remaining $2 \mathrm{ml}$. The original stock, resuspended pellet and supernatant were assayed by the double replica method as in Table 2 . \pm : standard deviation of result due to purely statistical errors.

Table 6. Immunological test of identity of carrier of defective lambda lysogeny with lambda phage

\section{Infecting phage}

Untreated suspension (prepared from u.v. induced CR $751\left(\lambda i_{1}, \lambda\right.$ v 1$\left.)\right)$

Suspension exposed to anti-lambda serum at $48^{\circ}$

Suspension exposed to control rabbit serum at $48^{\circ}$

Ratio of defective

Percentage of
plaque-formers
surviving
treatment
100

$5 \cdot 3$

64 to healthy lysogenic organisms formed from sensitive cells :

$L p^{i} / L p^{+} \times 100$

$8 \cdot 7 \pm 1 \cdot 2$

$6 \cdot 3 \pm 2 \cdot 1$

$10 \cdot 3 \pm 2 \cdot 5$

Separate portions of the suspension were exposed for $4 \mathrm{hr}$. at $48^{\circ}$ to anti-lambda rabbit serum previously absorbed by bacteria, and to control rabbit serum. Fractions of these and of the original suspension were assayed by the double replica method as in Table 2 . \pm : standard deviation of result due to purely statistical errors.

The carrier of defective lysogeny is not, however, a mere appendage or incorporated part which confers on normal lambda a low probability of defective lysogenization. When cultures of defective lysogenic organisms were induced by exposure to u.v. light the resulting suspensions contained a few particles able to confer defective lysogeny upon sensitive bacteria. Although these defective phage appeared to be much fewer in number than the bacteria which liberated them, they outnumbered the plaque-forming lambda phage in the same suspensions by a factor of 100 or more. For example, a suspension prepared by the $u . v$. induction of $\mathrm{C} 33\left(\lambda i_{2}\right)$ contained $1.9 \times 10^{3} / \mathrm{ml}$. plaque- 
forming lambda particles, but was able to form $2 \times 10^{5} / \mathrm{ml}$. defective lysogenic organisms upon infection of the sensitive strain $\mathrm{C} 112$.

We conclude that the carrier of defective lysogeny is defective lambda phage, in the special sense that it carries the genetic defect responsible for defective lysogeny.

Table 7. Specific adsorptive test of identity of carrier of defective lambda lysogeny with lambda phage

$\begin{array}{lcc}\text { Infecting phage } & \begin{array}{c}\text { Percentage of } \\ \text { plaque-formers } \\ \text { surviving } \\ \text { treatment }\end{array} & \begin{array}{c}\text { Ratio of defective } \\ \text { to healthy lysogenics } \\ \text { formed in sensitive } \\ \text { organisms }: L p^{i} / L p^{+} \times 100\end{array} \\ \begin{array}{l}\mathbf{7 5 1}\left(\lambda i_{1}, \lambda \text { v } 1\right) \text { ) } \\ \text { exposed to } \lambda \text {-sensitive organisms }\end{array} & 100 & \mathbf{9 \cdot 5} \pm \mathbf{2 \cdot 2} \\ \text { exposed to } \lambda \text {-resistant }\left(V_{\lambda}^{r}\right) \text { organisms } & 100 & \begin{array}{c}12 \cdot 0 \pm 3 \cdot 5 \\ 18 \cdot 0 \pm 4 \cdot 0\end{array}\end{array}$

Untreated suspension (prepared from u.v. induced $\mathrm{Cr} 751\left(\lambda i_{1}, \lambda\right.$ v 1$\left.)\right)$

Suspension exposed to $\lambda$-sensitive organisms

Suspension exposed to $\lambda$-resistant $\left(V_{\lambda}^{r}\right)$ organisms 100 $18 \cdot 0 \pm 4 \cdot 0$

Separate portions of the suspension were exposed for $15 \mathrm{~min}$. at $37^{\circ}$ to bacteria at a concentration of $2 \cdot 10^{8} / \mathrm{ml}$. In one case the bacteria were $l a m b d a$-sensitive (C 600): in the other lambda-resistant (C $600 / \lambda)$. The bacteria were removed by $5 \mathrm{~min}$. centrifugation at $7000 \mathrm{~g}$ at $4^{\circ}$, and each sample was sterilized with chloroform. Portions of each sample and of the original suspension were assayed by the double replica method as in Table $2 . \pm$ : standard deviation of result due to purely statistical errors.

\section{DISCUSSION}

Defective lysogeny of a kind similar to that investigated here was first described by Lwoff \& Siminovitch (1951) in a strain of Bacillus megaterium. Biochemical evidence led Siminovitch (1951) to conclude that the defect in their

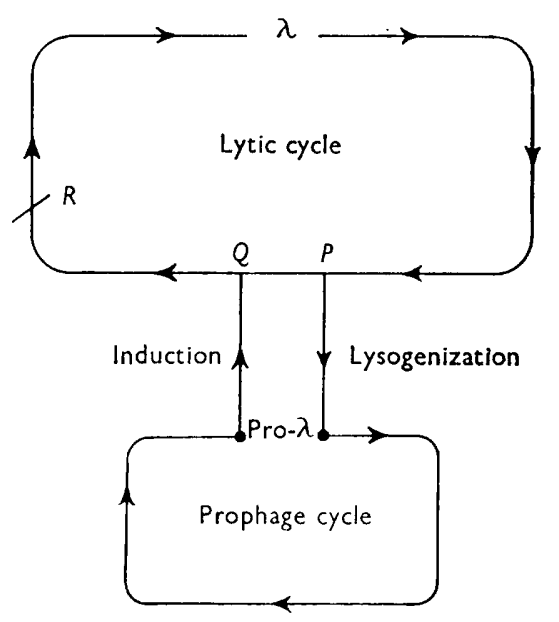

Fig. 1. The location of the block in the life-cycle of defective lambda phage.

strain brought about a failure to resume synthesis of deoxyribonucleic acid after u.v. induction. The existence of defective lysogeny was recognized in Escherichia coli by Lederberg \& Lederberg (1953). I have previously 
concluded (Appleyard, 1954b) that the defect in the lysogeny is caused by a mutation of a prophage gene.

The present experiments show that the mutant characters concerned in two such defects can be incorporated into extracellular lambda phage. The prophage genes controlling these defects therefore, like other known prophage genes (Appleyard, 1954b), appear to be transmissible to mature phage: their existence is not limited to the prophage state. Because defective phage particles form no plaques, it is apparent that each defect constitutes a block in the lifecycle of the phage at some point during the lytic cycle beyond $Q$, in Fig. 1 . Such a hypothetical block has been inserted at $R$ in that figure.

\section{REFERENCES}

APPLEYARD, R. K. (1954a). Segregation of lambda lysogenicity during bacterial recombination in $E$. coli K12. Genetics, 39, 429.

APPLEYARD, R. K. (1954b). Segregation of new lysogenic types during growth of a doubly lysogenic strain derived from $E$. coli K 12. Genetics, 39, 440.

Lederberg, E. M. \& Lederberg, J. (1953). Genetic studies of lysogenicity. Genetics, 38, 51.

Lederberg, J. \& Lederberg, E. M. (1952). Replica plating and indirect selection of bacterial mutants. J. Bact. 63, 399.

Lwoff, A. \& Simivovitch, L. (1951). Induction de la lyse d'une bactérie lysogène sans production de bactériophage. C.R. Acad. Sci., Paris, 233, 1397.

Markovitch, H. (1954). A quantitative biological test sensitive to low doses of ionizing radiations. Nature, Lond. 174, 796.

Siminovitch, L. (1951). Relation entre le développement abortif de prophage chez B. megatherium 91 (1) et la synthèse de l'acid désoxyribonucléique. C.R. Acad. Sci., Paris, 233, 1694.

Weigle, J. J. \& Delbrück, M. (1951). Mutual exclusion between an infecting phage and a carried phage. J. Bact. 62, 301. 